\title{
DIFFUSE CEREBRAL DEGENERATION IN INFANCY (ALPERS' DISEASE)
}

\author{
BY \\ W. BLACKWOOD, P. H. BUXTON, J. N. CUMINGS, D. J. ROBERTSON and S. M. TUCKER \\ From the Institute of Neurology, Queen Square, Maida Vale Hospital for Nervous Diseases, \\ and the Middlesex Hospital
}

(RECEIVED FOR PUBLICATION JULY 18, 1962)

In 1931 Alpers described a condition in which there was a peculiar form of degeneration of the cerebral grey matter. Subsequently other examples of this disorder in association with epilepsy, spasticity, myoclonus and dementia in early life have been published. These 24 cases, together with eight of their own, have been summarized by Wolf and Cowen (1954) under the name of 'diffuse progressive cerebral cortical atrophy', although the cerebellum and basal ganglia were also involved. As the condition is uncommon it was thought worth while to record five cases, occurring in three families, in which cerebral biopsy was performed; on the four which subsequently died, histological and chemical examination of the brain was carried out.

\section{Case Reports}

Case 1. The health of the parents had been good. There was no known family history of epilepsy or mental illness. An only sibling constitutes the second case of this report.

This full-term male infant was the product of the mother's first pregnancy and weighed $6 \frac{1}{2} \mathrm{lb} .(2 \cdot 9 \mathrm{~kg}$.). The membranes ruptured 48 hours before delivery and labour lasted 24 hours. The child was shocked at birth and appeared cyanotic one hour later; oxygen was administered. He was apparently well when discharged from hospital on the tenth day.

Diphtheria-pertussis inoculations were given at 6,7 and 8 months, and vaccination was carried out at 10 months, without complications.

At 10 months of age the child broke a femur and was in hospital for six weeks. There was no apparent head injury.

The parents thought that the child developed normally until the age of 15 months. He sat at 6 months if supported. At 10 months he could form simple phrases but was unable to crawl. However, the clinicians considered from a review of home movies, that motor retardation had begun at about 8 months of age.

The first convulsion, which occurred at 15 months, began with extension of the right hand in a claw position; the child 'shivered', fell forward limp and remained unconscious for four hours; clonic movements of the extremities then occurred. The patient was observed in hospital for 10 days; temperature and cerebrospinal fluid were normal.

During the next two months the patient became less active and more irritable. A second convulsion, similar to the first, occurred at 17 months, and subsequently there were progressively more frequent episodes of jerking of the extremities with hyperextension of the back, without loss of consciousness.

At 23 months of age focal seizures began. These were characterized by loss of consciousness and twitching of the left side of the face and left arm, each lasting 30 to 60 seconds. These occurred with increasing frequency, being almost continuous when the patient was admitted to hospital.

The patient was admitted to the National Hospital, Queen Square, at the age of 24 months, on January 13, 1958, under the care of Dr. E. A. Carmichael. He was a physically well-developed child who was inattentive to his surroundings, did not speak, and was unable to maintain the sitting position. There were frequent myoclonic jerks of all extremities. Head circumference was $45 \mathrm{~cm}$.

The child occasionally followed objects and persons with his eyes. Both optic discs were pale; the maculae were normal. He responded to sounds. The left arm was held immobile by the side; there were spontaneous movements of the other limbs but strength was reduced. Deep reflexes were brisk and symmetrical; there was bilateral ankle clonus, and plantar responses were extensor. Abdominal reflexes were present. He responded to light touch and painful stimuli applied to the trunk and limbs; less response was obtained in the lower extremities.

The child remained in hospital for 17 months, until his death at the age of $3 \frac{1}{2}$ years. During this time there was progressive deterioration. Myoclonic jerks occurred almost continuously for the first year, despite medication, then became less frequent and ceased entirely during the last few weeks. He became blind during the first year in hospital, and pupillary reflexes disappeared. Sucking 
and swallowing ceased, and nutrition was maintained by gastric tube. During the last few weeks of life the child lay motionless and non-responsive. There was marked spasticity of the limbs; the deep reflexes were hyperactive until terminally when they disappeared. Death followed a respiratory infection.

Investigations. Haemoglobin was $13 \cdot 3 \mathrm{~g}$. per $100 \mathrm{ml}$. on admission to hospital, falling to $8.9 \mathrm{~g}$. per $100 \mathrm{ml}$. before death. White blood cells numbered 11,800 per c.mm.; there was a normal differential count. Wassermann reaction was negative.

Bone marrow at 31 months was slightly hyperplastic; there were no abnormal cells. Urine at 37 months did not contain any metachromatic material. Cerebrospinal fluid at 27 months revealed 2 lymphocytes per c.mm.; there were no erythrocytes. Protein was less than $10 \mathrm{mg}$. per $100 \mathrm{ml}$. Pandy test was negative. Lange 0121000000 . Wassermann reaction was negative. At 36 months white blood cell count revealed 4 lymphocytes per c.mm.; erythrocytes, 3,000 per c.mm.; protein, $40 \mathrm{mg}$. per $100 \mathrm{ml}$.; Pandy test doubtful; Lange 5554420000; Wassermann reaction negative.

Radiographs of skull and chest at 24 months showed no abnormality. A ventriculogram at 24 months showed, 'Both lateral ventricles, the third ventricle, aqueduct and fourth ventricle have been well demonstrated. There is enlargement of both lateral ventricles, but no displacement. Air has passed out of the ventricular system over the cerebral cortex and marked cerebral atrophy has been demonstrated. No other abnormality has been seen.'

Toxoplasmosis test at 23 months was negative. Electroencephalogram: Several records were made. Initially at 24 months there were bilateral slow waves (2-4 c.p.s.) from both sides, but of smaller amplitude on the right, and numerous irregular spike-and-wave forms on the left. Two weeks later the asymmetry was no longer present. A record at the age of 29 months showed a background almost devoid of rhythmic activity, with enormous numbers of transient discharges at intervals of about one per second, showing great variation in form and distribution. At 33 months, the record was of low voltage, free of spike activity and consisted only of irregular slow waves. The pattern persisted until death. Cortical biopsies at 25 and 27 months revealed on both occasions that the cortex as described by the surgeon was atrophic and the white matter unusually firm. A thin subdural hygroma was found over the left occipital lobe on the occasion of the second biopsy.

The histological and chemical findings are reported later.

Case 2. An infant girl, admitted at the age of 19 months, birth weight $6 \frac{1}{2} \mathrm{lb}$. $(2.9 \mathrm{~kg}$.), was a sister of Case 1 and was born six months after the latter's death. There was normal neonatal progress until 12 months of age, when mental and physical development began to deteriorate. Episodic jerking was noted with hyperreflexia, and the first convulsion occurred at 16 months. She was admitted to hospital (Dr. P. H. Sandifer) where she was noted to have bilateral optic atrophy, was apparently deaf and was non-responsive.

Investigations. Haemoglobin was $12 \cdot 8 \mathrm{~g}$. per $100 \mathrm{ml}$.; white blood cells numbered 15,600 c.mm.; neutrophils $69 \%$. No metachromatic substance was found in the urine, but there was raised lysine, histidine and cystine. In the rerebrospinal fluid there was 1 lymphocyte per c. $\mathrm{mm}$.; protein $10 \mathrm{mg}$. per $100 \mathrm{ml}$. The electroencephalogram showed generalized abnormality with asymmetry between the activities of the two hemispheres. A cortical biopsy of the right frontal region revealed the following: 'The subarachnoid space was moderately deep. The underlying gyri were rather shrunken, but of normal colour and consistency.' The histological and chemical findings are described later.

Case 3. A full-term female infant was admitted on May 21, 1957, at the age of 11 months (Dr. E. W. Hart), birth weight $6 \mathrm{lb} .7 \mathrm{oz}$. $(2.9 \mathrm{~kg}$.). She had progressed normally until the age of 11 months, when she began shrugging shoulders; this was followed by vomiting and twitchings involving all four limbs. Frequent akinetic seizures developed despite sedation and these gradually increased in frequency and severity. Fundi were normal.

Investigations. Haemoglobin $11 \mathrm{~g}$. per $100 \mathrm{ml}$; electrolytes consistently normal. Chromatography revealed normal urine. The cerebrospinal fluid had 1 lymphocyte per c.mm.; protein $160 \mathrm{mg}$. per $100 \mathrm{ml}$. An air encephalogram had a normal pattern; an electroencephalogram showed severe generalized abnormality. Cortical biopsy was taken on October 22, 1957.

Her general condition deteriorated over 10 months with continuing convulsions until death at 20 months on March 12, 1958. The histological and chemical findings are described later.

Case 4. This case, admitted on June 1, 1959 (Dr. E. W. Hart), was the brother of Case 3. His birth weight was $7 \frac{1}{2} \mathrm{lb}$. $(3.4 \mathrm{~kg}$.) and delivery was normal. He progressed normally until the age of 18 months, when he began vomiting and failed to thrive. Twitchings of limbs, especially left side, were now noted, and these were later replaced by myoclonic type movements of greater severity and increased frequency. Fundi were pale, liver and spleen were not palpable.

Investigations. Haemoglobin $14 \mathrm{~g}$. per $100 \mathrm{ml}$; white blood cells numbered 17,700 per c.mm.; electrolytes were normal. There was excess of histidine and glutamic acids on chromatography of urine. Cerebrospinal fluid revealed 1 lymphocyte per c.mm.; protein $140 \mathrm{mg}$. per $100 \mathrm{ml}$. The electroencephalogram was abnormal but non-specific pattern. Cortical biopsy was taken on July 6, 1959.

Myoclonic convulsions continued with hyperreflexia and gradual deterioration. The child died on July 13, 1959 , at the age of 10 months, following a laparotomy for intestinal obstruction. The histological and chemical findings are described later.

Case 5. A female infant, youngest of six children, was admitted on August 28, 1958 (Dr. P. H. Sandifer). Her 
birth weight was $8 \mathrm{lb}$. (3.6 kg.). She had a normal delivery and neonatal life. A brother, the fourth child in the family, developed normally for 10 weeks, then began to have convulsions, failed to thrive and died at the age of 18 months. A clinical diagnosis of cerebral atrophy with compensatory hydrocephalus was made. Case 5 developed normally until the age of 10 weeks, when convulsions first occurred. These continued for the next four months almost daily, associated with marked rigidity and hyperreflexia. Frequent myoclonic convulsions occurred subsequently until her death at the age of $11 \frac{1}{2}$ months.

Investigations. These were carried out when the infant was between 6 and $7 \frac{1}{2}$ months. Haemoglobin was $12.6 \mathrm{~g}$. per $100 \mathrm{ml}$; white blood cells: 14,000 per c.mm. No abnormal constituents were present in the urine. The cerebrospinal fluid had no cells; protein $20 \mathrm{mg}$. per $100 \mathrm{ml}$. An air encephalogram revealed cerebral atrophy. An electroencephalogram showed abnormality with gross asymmetry between the two sides, and a fairly extreme cortical lesion was suggested. Cortical biopsy revealed an extremely deep subarachnoid space with a rough arachnoid membrane and with side sulci. The gyri were firm and pale.

\section{Pathological Findings}

Methods. The cerebral biopsy specimens were fixed in formol-saline. Scharlach R, haematoxylin P.A.S., toluidine blue, Cajal's gold chloride, Bielschowsky and Hortega's microglial stains were performed on frozen sections, and haematoxylin and eosin, haematoxylinvan Gieson and Loyez stains on paraffin sections.

Numerous sections of several regions of the brains and spinal cord obtained at autopsy were embedded in celloidin, and stained by haematoxylin van Gieson, Nissl, Loyez, Gross-Bielschowsky and P.A.S. techniques. Frozen sections of selected regions were stained by Scharlach R, haematoxylin, toluidine blue, P.A.S., Cajal's gold chloride and Holzer.

\section{Case 1}

Brain Biopsies. The specimens, obtained at 25 and 27 months, were similar and are described together.

Cortical lamellation was well preserved and the number of nerve cells was not appreciably diminished. Macrophages distended with sudanophilic material were present in all layers, but principally in the first, fifth and sixth. Most were distributed singly, but occasionally were aggregated in groups of two or three. There was a diffuse increase in astrocytes with many nuclear pairs in all layers. Rather dense gliosis of the subpial zone was present.

In the white matter, myelin sheaths were moderately well preserved. However, occasional myelin balls were found and numerous fat-filled macrophages were scattered throughout the specimens, along groups of fibres, and clustered perivascularly. These changes were well marked in the subcortical region as well as more deeply. Astrocytes showed pronounced hypertrophy and hyperplasia.

The lipid in both cortex and white matter was sudano- philic, non-metachromatic and anisotropic. A few P.A.S.-positive granules were present in some of the macrophages.

Autopsy Findings (three and a half hours after death). There was severe bilateral bronchopneumonia. The viscera, including the liver, lymph nodes, peripheral nerves and muscles were unremarkable on gross and microscopic examination.

The brain weighed $435 \mathrm{~g}$. The subarachnoid space was greatly enlarged. The brain was shrunken, with small gyri and broadened sulci, these changes being most severe in the occipital and temporal lobes. Cut sections of the unfixed brain showed a great loss of central white matter and ventricular dilatation (Fig. 1a, b and c). The cortex showed two zones-the outer being grey, and the inner reddish brown. Both grey and white matter were very firm and tough.

The left cerebral hemisphere and left cerebellar hemisphere were submitted for chemical study and the remainder of the brain and cord was fixed in formolsaline for histological examination.

\section{Microscopic Findings}

(a) Cerebral hemisphere: There was histological evidence to suggest that marked progression of the lesions had occurred in the one and a half year period between the cortical biopsies and death. Whereas earlier, considerable myelin had been present, there was now virtually complete demyelinization of the hemisphere examined, only a few myelinated fibres remaining in the internal capsule and basal ganglia. Axons were correspondingly diminished. Fat-laden phagocytes were present in small numbers throughout the hemisphere, but were notably less numerous than in the biopsies. There was very marked astrocytic gliosis throughout the white matter.

The cortex was abnormal in all regions examined, the temporal, postero-frontal and occipital lobes being most affected. There was moderate loss of neurones from all layers, particularly in the outer half of the cortex, and in the severely altered regions there was status spongiosus of the second and outer layers. Gliosis, present throughout the cortex, was most marked in the outer third and again in the deeper layers. The inner part of the third layer tended to be least involved (Figs. 2 and 3).

(b) Basal ganglia: The thalamus was markedly shrunken, with gross reduction in neurones and very dense gliosis. The globus pallidus was largely devoid of nerve cells and myelin and contained many macrophages. Gliosis was dense. The caudate nucleus and putamen were essentially uninvolved. Only occasional myelin sheaths remained in the optic tract, and there was wellmarked gliosis. The cortico-spinal tracts of the brainstem showed pallor of myelin staining, with gliosis and a few macrophages. The pontine tegmentum contained an excessive number of prominent microglial nuclei and some phagocytes, but there was no obvious loss of myelin or loss of neurones. The inferior olives were intact. In the cerebellum, the cortex showed extensive degeneration involving the posterior aspect of the vermis and hemispheres, most marked at the apices of the folia and 

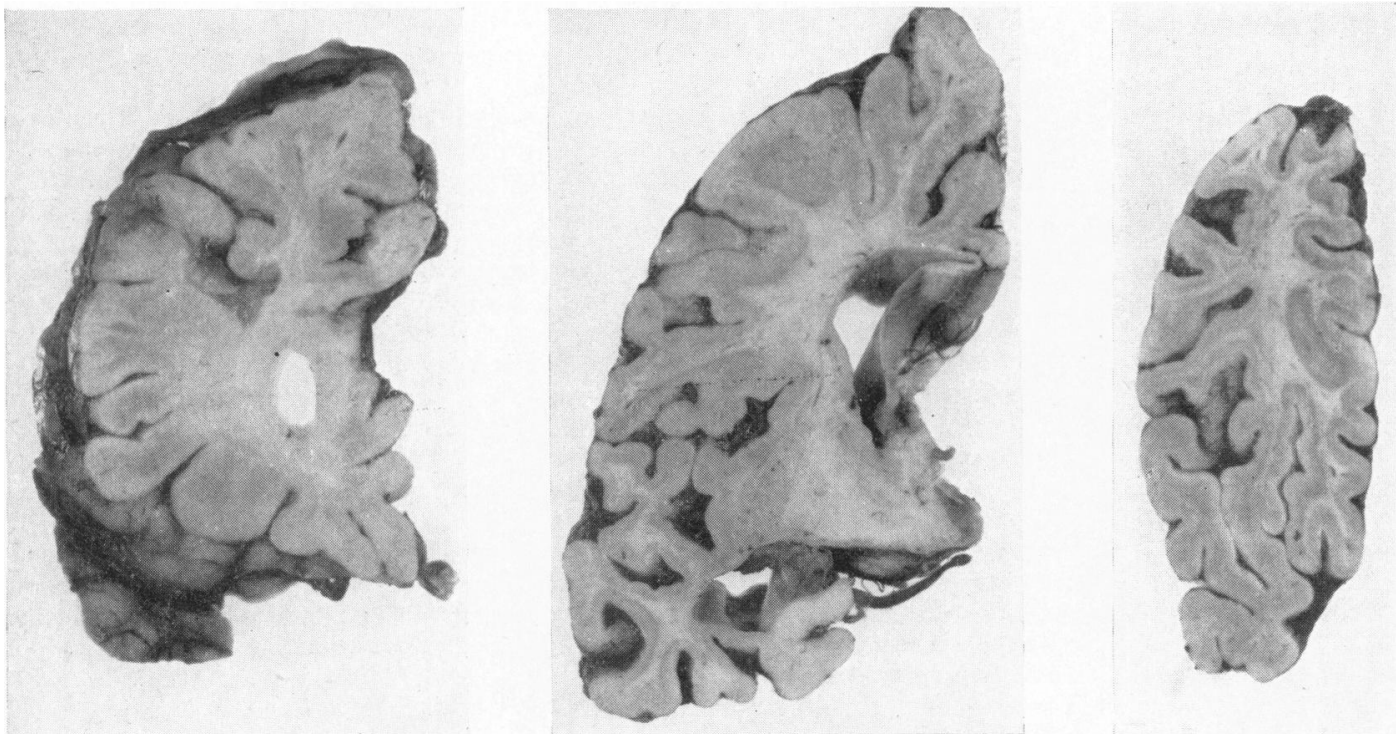

a

b

FIG 1a, b, c. Case 1: Coronal sections, frontal, central and occipital, showing shrinkage of hemisphere, due to thinning of the cortex and loss of white matter, with widening of sulci and enlargement of ventricles. In the frontal slice (a) the scar of the biopsy can be seen (top left).

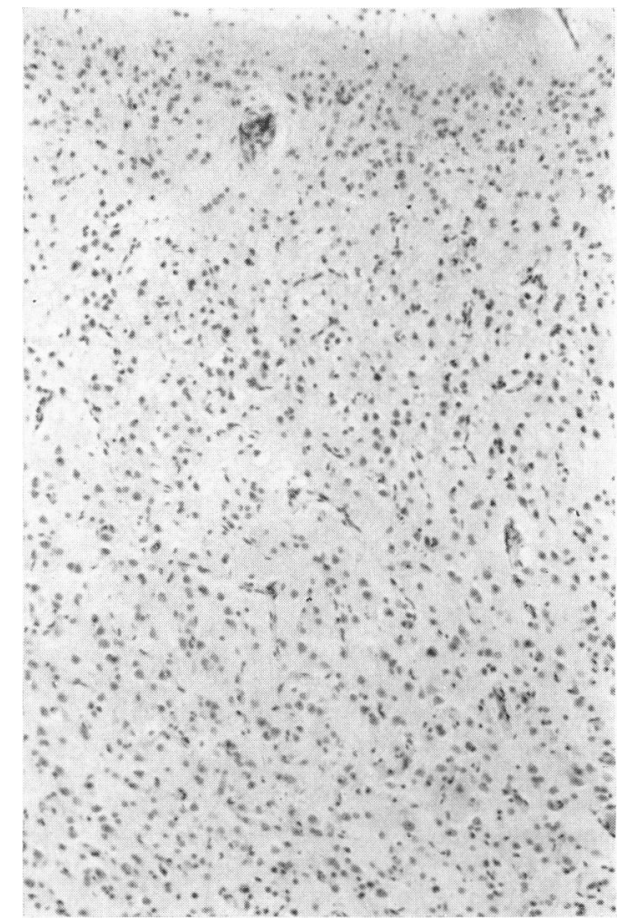

FIG. 2.-Case 1: Insular cortex, showing relative preservation of laminar pattern, loss of nerve cells but increase of glia. (Celloidin section stained haematoxylin van Gieson $\times 84$.)

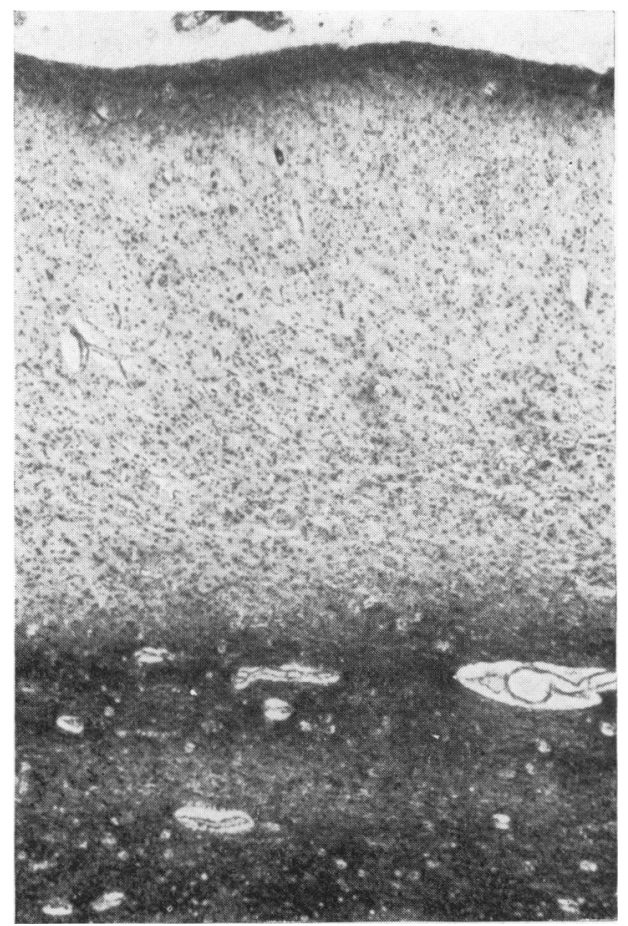

FIG. 3.-Case 1: Insular cortex and white matter, showing an increase of astrocytic fibres in the superficial and deepest part of the cortex and in the white matter.

(Celloidin section stained phosphotungstic acid haematoxylin $\times 45$.) 


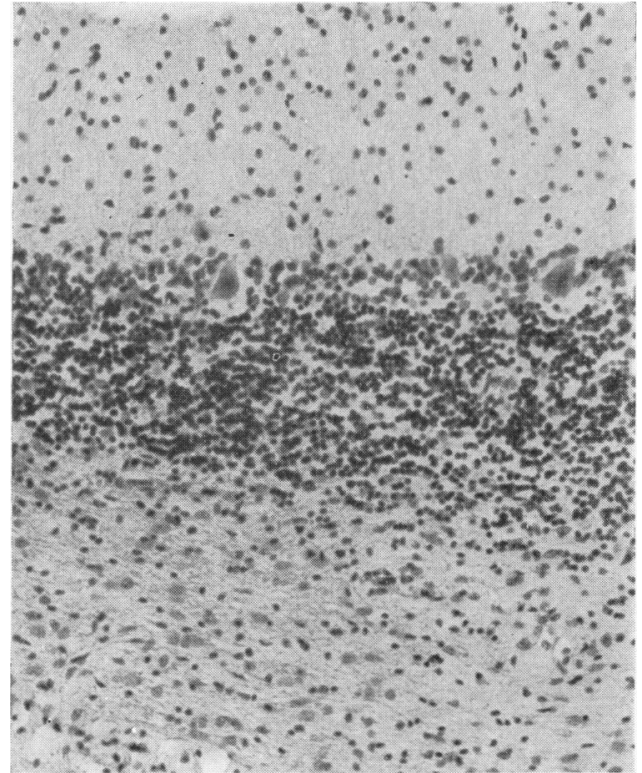

FIG. 4.-Case 1: Cerebellum, showing few Purkinje cells and granule cells with an increase in number of Bergmann astrocytes and of astrocytes in the white matter.

(Haematoxylin van Gieson $\times$ 144.)

least marked in their bases. In the involved areas both granule and Purkinje cells were diminished in number. A few empty baskets were found, and very occasional 'torpedoes' were present on axons of surviving Purkinje cells. There was marked proliferation of Bergmann astrocytes with dense glial fibre formation. In the white matter, there was partial loss of axons and myelin, and numerous fat-filled macrophages were present (Figs. 4 and 5). In the dentate nucleus the most prominent change was an intense gliosis. Nerve cells were very reduced in number.

(c) The Spinal Cord: In the crossed pyramidal tracts there was a diffuse reduction of myelinated nerve fibres.

The leptomeninges were slightly thickened in some places and normal elsewhere. Apart from slight adventitial fibrous thickening of capillaries in the most severely involved areas of cortex, inflammatory infiltration of meninges or perivascular spaces was not found.

Case 2. The changes were essentially similar to those seen in the biopsies from the first case.

\section{Case 3}

Brain Biopsy. Cortical lamination was still discernible, but there was loss of nerve cells and degenerate forms, particularly in the 3rd and 5th layers. There was a marked microglial increase in all layers of the cortex and endothelial hyperplasia of blood vessels, most apparent in the deeper layers, where there was a marked fibrillary gliosis.

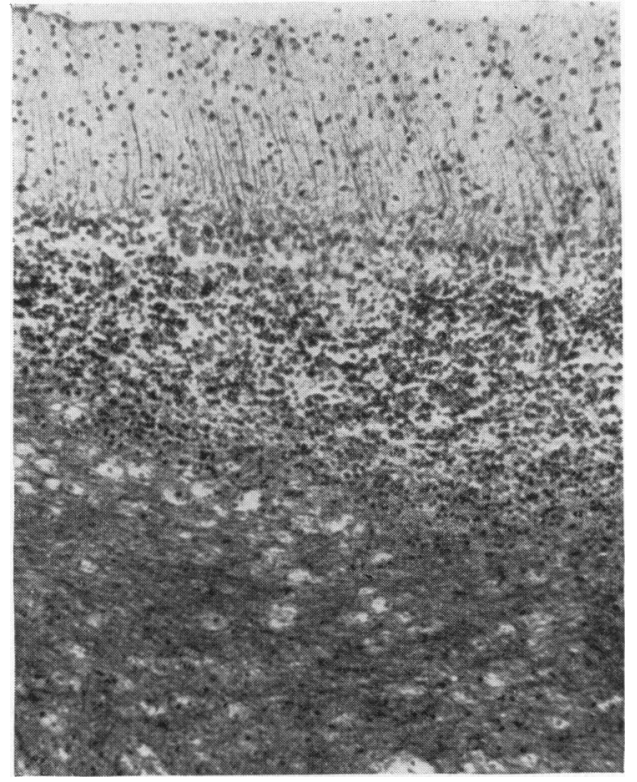

FIG. 5.-Case 1: Cerebellum, showing dense glial fibre formation in the molecular layer and in the white matter. (Phosphotungstic acid haematoxylin $\times 124$.)

There was a general loss of myelin in the white matter with areas of complete demyelination, particularly subcortically, that produced patchy status spongiosus. Axons were generally diminished in number and absent in the demyelinated areas; there was no sparing of the tangential fibres.

Lipid stains showed many sudanophilic macrophages both in the cortex and in even greater numbers in the white matter. These cells were diffusely scattered without clear perivascular arrangement. The lipid material was P.A.S. negative, and it did not stain metachromatically with toluidine blue. It was anisotropic.

Autopsy Findings. The body was very wasted. There was bilateral confluent bronchopneumonia and a lung abscess. The liver had a normal weight of $480 \mathrm{~g}$. but was rather pale.

The brain weighed $600 \mathrm{~g}$. The arachnoid showed gelatinous thickening to 0.25 in. $(6 \mathrm{~mm}$.), with occasional cortical adhesions in most areas. The brain was firmer than normal and this was particularly so in the occipital lobes. There appeared to be a zone of cleavage between grey and white matter. The carotid and vertebral arteries and main vessels of the circle of Willis were normal.

\section{Microscopic Findings}

(a) Liver: Early cirrhosis, infiltration of portal tracts by lymphocytes and polymorphs, some proliferation of bile-ducts and increased connective tissue extending around lobules. No distension of bile-ducts or portal 


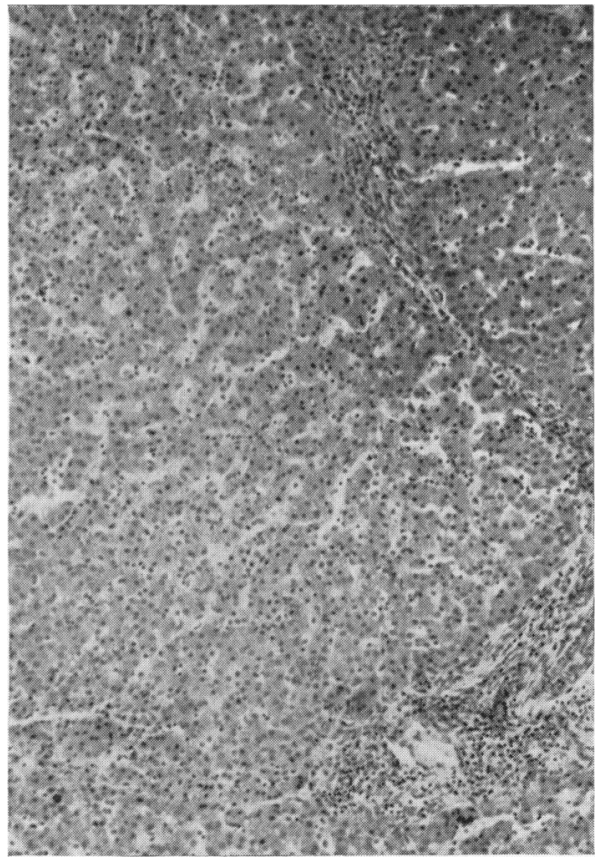

FIG. 6.-Case 3: Liver, showing cellular infiltration of portal tracts and occasional vacuolation of parenchymal cells. (Haematoxylin and eosin $\times 80$.)

veins. Some of the more central parenchymal cells showed vacuolation with flecks of yellow pigment, probably bile pigment. These vacuolated cells gave the staining reactions of neutral fats and did not stain with

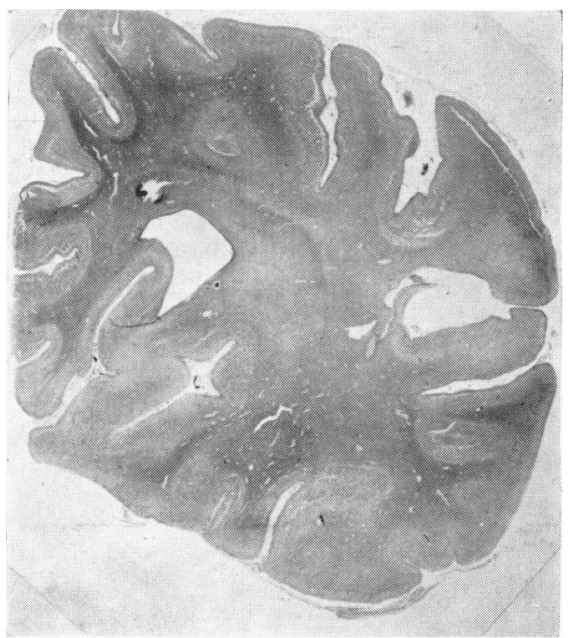

FIG. 7.-Case 3: Occipital lobe, showing diffuse demyelination most marked around the posterior horn of the ventricle. Extensive cortical laminar necrosis is also seen.

(Heidenhain method for myelin $\times 1 \cdot 4$.)

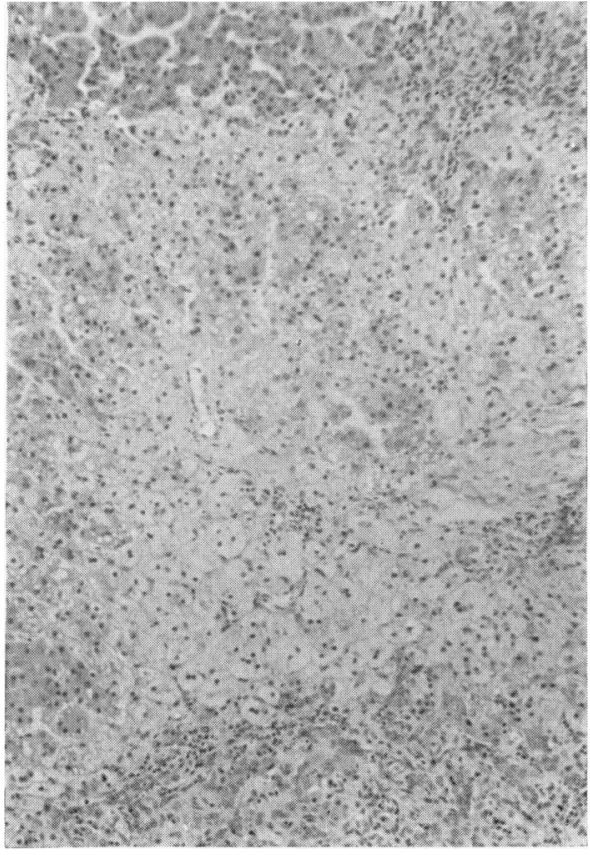

FIG. 9.-Case 4: Liver, showing large vacuolated cells towards centre of lobule; portal cellular infiltration, and fringe of surviving parenchymal cells.

(Haematoxylin and eosin $\times 80$.)

P.A.S. or glycogen stains. The apparently healthy liver cells stained normally (Fig. 6).

(b) Cerebral hemispheres: The cortex was very

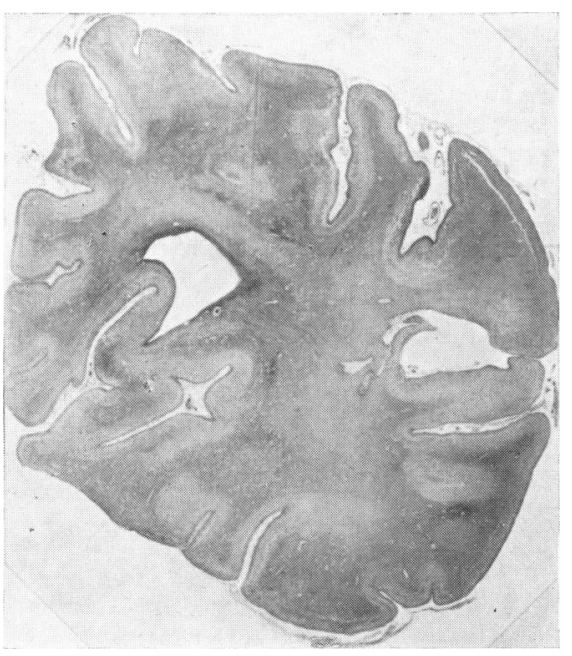

FIG. 8.-Case 3: Serial section of Fig. 7, showing gliosis in areas of myelin loss particularly around the ventricle. (Holzer method $\times 1.4$ for neuroglial fibres ) 
abnormal; extensive neuronal loss was apparent in all layers, particularly the $3 \mathrm{rd}$ and $5 \mathrm{th}$, where, in some areas of the occipital, temporal, insular and frontal regions, there was laminar necrosis and status spongiosus in the 2nd and 3rd layers. Capillary proliferation was marked in the most severely affected areas of the cortex. Diffuse gliosis was present throughout the grey and white matter, being most marked in the subpial and subependymal regions, and about blood vessels. Sections of the occipital lobe stained for myelin and for glia by Holzer's method showed complementary demyelination and gliosis (Figs. 7 and 8). There was a general diffuse loss of myelin and axons in the internal capsules and basal ganglia. The subcortical white matter was the most severely affected. The loss of myelin was not selectively perivascular, though in some areas it was more marked about vessels.

Fat stains showed sudanophilic material in macrophages scattered diffusely in all areas of the cortex and white matter or aggregated in small groups, occasionally in relation to vessels. The lipid material did not stain with P.A.S., nor was it metachromatic with toluidine blue; it was anisotropic.

Internal capsule, thalamus, globus pallidus, putamen and caudate were similar to Case 1. Subthalamic nucleus showed nerve cell loss; the remaining neurones showed marked degenerative changes, and moderate glial proliferation. Optic nerve: no apparent demyelination in the small piece available. Cerebellum: cortex showed considerable loss of Purkinje and granular cells, particularly in hemispheres, while the vermis was relatively spared. No definite folial pattern of degeneration could be discerned. Astrocytic gliosis as in Case 1. Dentate nucleus: considerable nerve cell loss and dense glial fibre formation. Inferior olive: moderate nerve cell loss and many degenerate forms, glial infiltrated but no neuronophagia.

\section{Case 4}

Brain Biopsy. Cortical lamination was well preserved, but the nerve cells in all layers apart from the subpial region were grossly distended in both frozen and paraffin sections. The distension was due to ballooning of the nuclei, which left a thin rim of darkly staining Nissl substance in the perikaryon. These distended cells failed to stain with fat stains or P.A.S. and would have been considered 'water change' artefact if it had not been for the microglial increase in all layers with early fibrillary gliosis in the deeper layers of the cortex and subcortical white matter.

There was minimal myelin and axon loss.

Lipid stains showed no free lipid and no lipid macrophages.

Autopsy Findings. The lungs showed bilateral bronchopneumonia; no abnormality of the gastro-intestinal tract could be seen; the spleen (weight $15 \mathrm{~g}$.) showed prominent malpighian corpuscles. The liver was small (285 g.), firm, tawny coloured, and slightly greasy on section. The brain (weight 735 g.) showed no obvious abnormality apart from the scar of the right frontal biopsy. The blood vessels and meninges appeared normal.

\section{Microscopic Findings}

(a) Liver: Extensive cirrhosis, fibrotic bands surrounding each lobule, bile-duct proliferation and lymphocytic infiltration in portal tracts. No distension of bile-ducts or portal veins.

Towards the centres of the lobules there were large parenchymal cells with vacuolated cytoplasm giving the staining reactions of neutral fat (they failed to stain with P.A.S. or glycogen stain, although the peripheral apparently healthy liver cells stained normally (Fig. 9)).

(b) Cerebral hemispheres: The changes were far less severe than those of the first case. There was a general moderate loss of cortical nerve cells, most marked in the third and fifth layers, but the cortical laminar pattern was preserved. Many of the nerve cells showed mild distension of their cytoplasm with occasional vacuolation. Nissl substance was lost and many such degenerating neurones had glial satellites.

Subpial and subependymal gliosis was present to a minor degree-far less than in Case 3. But there was some patchy fibrillary gliosis in the white matter, particularly of the occipital lobe.

Myelin loss was very patchy and of minor degree, most often found subcortically. Axon loss was also slight and in the same areas. The tangential, subcortical fibres were not preferentially affected.

Fat stains showed only very occasional sudanophilic macrophages; these were seen both in the cortex and white matter, mainly in the occipital lobe.

(c) Thalamus and subthalamic nuclei: No gross nerve cell loss; moderate increase in astrocytic nuclei. Globus pallidus showed slight nerve cell loss, some degenerate nerve cells with satellitosis. Mild glial fibre formation. Putamen and caudate were as in Case 1. Optic nerve was normal. Cerebellum: a few folia in the inferomedial part of the hemisphere and in the vermis showed loss of Purkinje cells and granular cells with proliferation of Bergmann astrocytes and fibrillary gliosis. The Obersteiner layer persisted over all the cerebellar folia except the affected ones. Slight nerve cell loss in the dentate nucleus, marked increase of astrocytic nuclei, and slight fibrillary gliosis. Inferior olive showed slight nerve cell loss, and moderate glial increase with scanty glial fibres were seen in Holzer preparations.

\section{Case 5}

Brain Biopsy (Figs. 10, 11a, b and c). Cortical architecture was well preserved, with no evident loss of nerve cells. There was a conspicuous increase in the number and size of microglia in all stages of transition between resting and compound granular cells, most evident in the first, fifth and sixth cortical layers. Scharlach $R$ preparations demonstrated these cells to contain abundant tiny drops and larger masses of sudanophilic material. Similar material was present in a few capillary endothelial cells. Astrocytes were moderately increased in number in the superficial cortex and much increased in the deeper layers.

In the white matter, myelin was moderately reduced in 


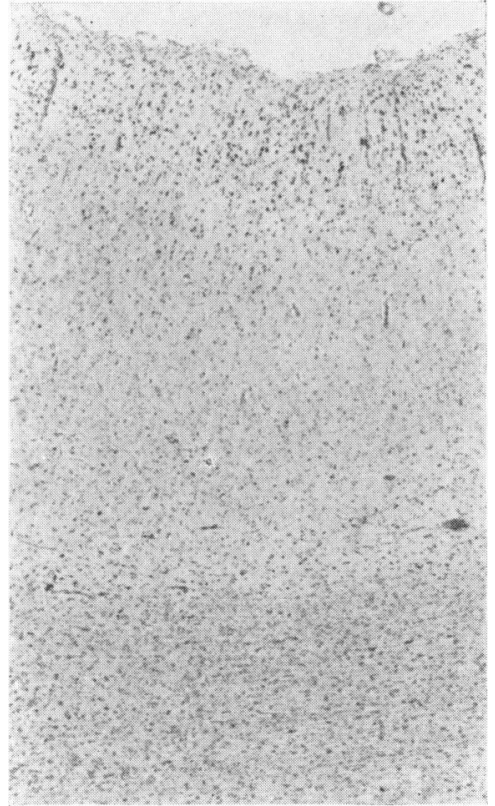

Fig. 10.-Case 5: Biopsy. Cortex and underlying white matter, frozen section (Scharlach $R$ haematoxylin $\times 30$ ), showing preservation of cortical architecture, and reduction in the number of myelin sheaths in the white matter.

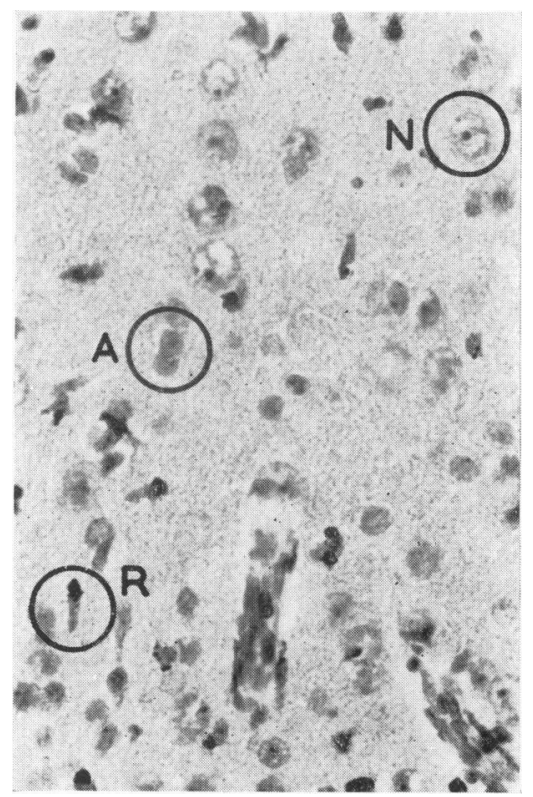

Fig. 11b. - Middle region of cortex from Fig. $8(\times 300)$. Note nerve cells $(N)$, rod cells $(R)$, and (A) a pair of astrocytic nuclei indicating hyperplasia.

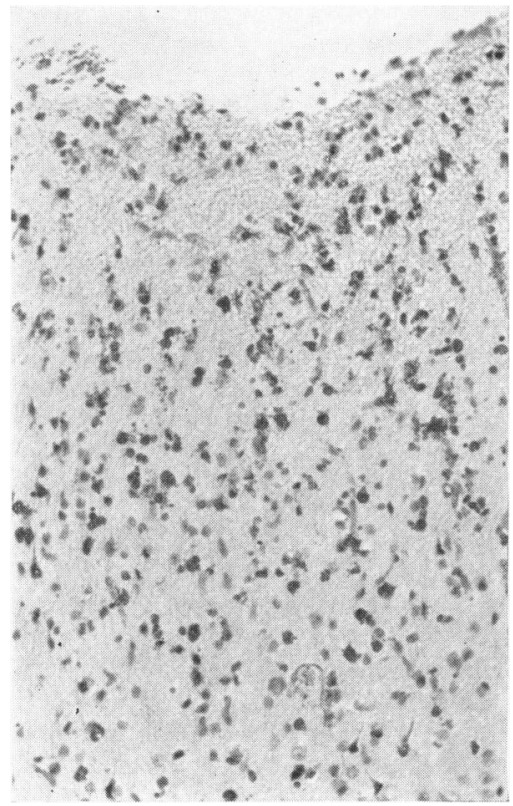

Fig. 11a.-Superficial portion of cortex from Fig. 10 at higher magnification $(x 130)$. Sudanophilic material appears dark. Note the abundance of such material in this region.

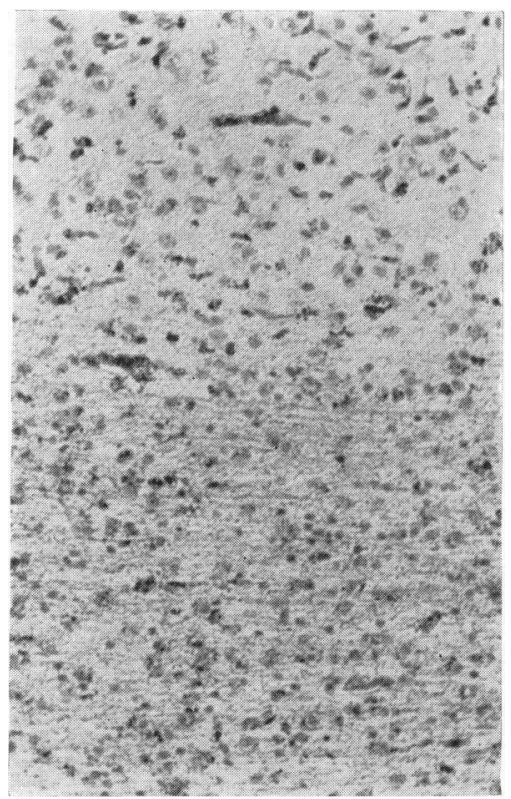

FIG. 11c.-Junction of cortex and white matter from Fig. $10(\times 130)$, showing sudanophilic lipid in the deepest layers of the cortex and reduction of myelin sheaths from the white matter, in which phagocytes containing fine sudanophilic particles are present. 
TABLE

CEREBRAL LIPIDS (g./100 g. dry tissue)

\begin{tabular}{|c|c|c|c|c|c|c|c|c|c|c|c|c|c|}
\hline \multirow[t]{2}{*}{ Substance } & & \multicolumn{2}{|c|}{$\begin{array}{l}\text { Autopsy on } \\
\text { Case 1, } \\
\text { at Age } \\
4 \text { years }\end{array}$} & \multicolumn{2}{|c|}{$\begin{array}{c}\text { Biopsy on } \\
\text { Case 2, } \\
\text { at Age } \\
1 \text { year } 6 \text { months }\end{array}$} & \multicolumn{2}{|c|}{$\begin{array}{c}\text { Autopsy on } \\
\text { Case } 3 \text {, } \\
\text { at Age } \\
2 \text { years } 1 \text { month }\end{array}$} & \multicolumn{2}{|c|}{$\begin{array}{l}\text { Autopsy on } \\
\text { Case 4, } \\
\text { at Age } \\
10 \text { months }\end{array}$} & \multicolumn{2}{|c|}{$\begin{array}{l}\text { Autopsy on } \\
\text { Case 5, } \\
\text { at Age } \\
1 \text { year }\end{array}$} & \multicolumn{2}{|c|}{$\begin{array}{l}\text { Normal } \\
\text { at Age } \\
3 \text { years }\end{array}$} \\
\hline & & White & Cortex & White & Cortex & White & Cortex & White & $\overline{\text { Cortex }}$ & White & Cortex & White & Cortex \\
\hline $\begin{array}{l}\text { Total phospholipid } \\
\text { Sphingomyelin .. } \\
\text { Total cholesterol .. } \\
\text { Esterified cholesterol } \\
\text { Cerebroside } \\
\text { Total hexosamine } \\
\text { Neuraminic acid ... } \\
\text { Water }(\%)\end{array}$ & $\begin{array}{l}\cdots \\
\cdots \\
\cdots \\
\cdots \\
\cdots \\
\cdots \\
\cdots\end{array}$ & $\begin{array}{l}12 \cdot 3 \\
1 \cdot 78 \\
7 \cdot 8 \\
3 \cdot 3 \\
2 \cdot 9 \\
0 \cdot 28 \\
8 \overline{1 \cdot 4}\end{array}$ & $\begin{array}{c}15 \cdot 9 \\
0 \cdot 07 \\
6 \cdot 4 \\
1.5 \\
3 \cdot 5 \\
0 \cdot 46 \\
0 \cdot 30 \\
83 \cdot 9\end{array}$ & $\begin{array}{l}\frac{8 \cdot 3}{5 \cdot 6} \\
\frac{1 \cdot 7}{0 \cdot 38} \\
\overline{75 \cdot 9}\end{array}$ & $\begin{array}{l}15 \cdot 7 \\
\overline{2 \cdot 6} \\
0 \cdot 3 \\
\overline{-} \\
\overline{0 \cdot 21} \\
73 \cdot 8\end{array}$ & $\begin{array}{l}12 \cdot 3 \\
3 \cdot 7 \\
13 \cdot 3 \\
4 \cdot 9 \\
8 \cdot 1 \\
0 \cdot 23 \\
8 \overrightarrow{81 \cdot 1}\end{array}$ & $\begin{array}{c}12 \cdot 4 \\
2 \cdot 7 \\
8 \cdot 5 \\
2 \cdot 6 \\
5 \cdot 5 \\
\overline{0 \cdot 21} \\
88 \cdot 9\end{array}$ & $\begin{array}{c}21 \cdot 8 \\
7 \cdot 9 \\
14 \cdot 9 \\
1 \cdot 7 \\
16 \cdot 5 \\
0 \cdot 53 \\
83 \cdot 6\end{array}$ & $\begin{array}{c}16 \cdot 2 \\
3 \cdot 3 \\
8 \cdot 0 \\
0 \\
10 \cdot 6 \\
0 \cdot 72 \\
0 \cdot 26 \\
88 \cdot 2\end{array}$ & $\begin{array}{c}21 \cdot 2 \\
4 \cdot 9 \\
11 \cdot 1 \\
0 \cdot 6 \\
9 \cdot 8 \\
0 \cdot 55 \\
81 \cdot 3\end{array}$ & $\begin{array}{c}19 \cdot 2 \\
2 \cdot 7 \\
6 \cdot 4 \\
0 \cdot 4 \\
3 \cdot 4 \\
0 \cdot 67 \\
0 \cdot 33 \\
85 \cdot 4\end{array}$ & $\begin{array}{c}20 \cdot 1 \\
5 \cdot 0 \\
13 \cdot 1 \\
0 \\
16 \cdot 0 \\
0 \cdot 4 \\
75 \cdot 7\end{array}$ & $\begin{array}{c}15 \cdot 7 \\
4 \cdot 0 \\
6 \cdot 6 \\
0 \\
5 \cdot 0 \\
0 \cdot 7 \\
0 \cdot 37 \\
84 \cdot 7\end{array}$ \\
\hline
\end{tabular}

a diffuse distribution involving subcortical as well as deeper fibres. A large number of microglia containing sudanophilic material were widely distributed, showing little tendency for perivascular aggregation. Astrocytes were much hypertrophied and hyperplastic. Axons appeared as numerous as myelin sheaths.

Autopsy Findings. This was limited to examination of the central nervous system. The left half of the brain, fixed in $10 \%$ formol saline, and spinal cord were received from Dr. R. D. Clay, Central Laboratory, Portsmouth, who had performed the autopsy. The right half of the brain was submitted for biochemical study.

The brain was similar to Case 1 except that the frontal and temporal regions were most involved and the occipital least. Microscopic findings were similar to Case 1. The thalamus was similar to Case 1. The globus pallidus was preserved. In the putamen there was a diffuse increase in astrocytic nuclei and in several regions almost complete loss of nerve cells with dense fibrillary gliosis. The subthalamic nucleus was intact. Brain stem: no abnormality was found in the midbrain, pons or medulla. In particular the basis pontis and inferior olivary nuclei were intact. Cerebellum was similar to Case 1, but there was severe alteration of the cerebellar cortex involving particularly the superior surface of the hemispheres and the vermis. The cerebellar white matter and the dentate nucleus were not appreciably altered.

\section{Biochemical Findings}

Portions of cerebral white matter and cortex from the biopsy specimens and from the post-mortem material were examined for water content and various lipid substances.

The tissues were dried to constant weight at $37^{\circ} \mathrm{C}$. in vacuo and the water content estimated. Cerebral lipids were extracted by the procedure of Folch, Lees and Sloane Stanley (1957) using a $2: 1$ chloroformmethanol solvent $(v / v)$. Estimations on the extracts were made of total phospholipid, sphingomyelin, total and free cholesterol and of cerebroside (Cumings, 1953), hexosamine (Cumings, 1957), while the method for neuraminic acid employed followed the extractive procedure of Long and Staples (1959) with the colorimetric technique of Svennerholm (1957).
The results of these examinations in all five cases can be seen in the Table.

There is some loss of phospholipid, total cholesterol and of cerebroside in all cases in both the white matter and the cortex, although the changes are less marked in Cases 4 and 5, more particularly in the white matter. Esterified cholesterol is present in excess in four out of five cases. In Case 4 there was no esterified cholesterol in the cortex, and in Case 5 the amounts present were not significant. Total hexosamine and neuraminic acid were not abnormal in any of the five cases.

The results of the examination of the biopsy specimens were not significantly different from the results obtained on examination of the post-mortem specimens of brain tissue.

These findings indicate a quite definite degree of demyelination and damage to the white matter and the cerebral cortex.

\section{Discussion}

Diffuse progressive degeneration of the brain as a cause of progressive dementia in early life is less commonly reported than the lipidoses and leucodystrophies. Alpers (1931) described an example of such a condition under the title of 'Progressive diffuse degeneration of the grey matter of the cerebrum', and his name is often used as an eponym (Greenfield, Blackwood, McMenemey, Meyer and Norman, 1958). Other descriptive terms applied to similar reported cases include 'poliodystrophia cerebri progressiva (infantilis)' (Christensen and Krabbe, 1949), 'diffuse cortical sclerosis' (Rusk and Nixon, 1927) and 'familial degeneration of the grey matter in childhood' (Ford, Livingston and Pryles, 1951). Wolf and Cowen (1954), in an extensive review of the literature, cited 24 previously reported examples and added eight cases under the heading 'diffuse progressive cerebral cortical atrophy'.

The clinical features, as carefully summarized by Wolf and Cowen (1954), were: normal development for several weeks, months, or years, then motor and mental retardation with focal or generalized convulsions, myoclonic jerking, occasional blind- 
ness, choreoathetosis and tremor. In all cases the course was one of progressive deterioration with development of profound dementia and spastic paralysis. Death occurred in half the cases within five and a half years; one exceptional case survived for 69 years.

Ford et al. (1951) divided eight cases, on the basis of their clinical courses, into two groups:

(a) An infantile group, in which symptoms appeared during the first year of life, and here the longest survival was two and a half years.

(b) A juvenile group, characterized by an onset between 3 and 6 years of age, and with a duration as long as 16 years.

The five cases in the present report fall into Ford's infantile group; the age of onset of these cases varied between 10 weeks and 12 months, and the longest survival from the onset of symptoms was three and a half years (Case 1).

The pathological findings in the cases reviewed by Wolf and Cowen (1954) consisted principally of widespread loss of neurones with microglial proliferation and astrocytic gliosis. The lesions were most severe in the cerebral and cerebellar cortices and thalamus, and were frequently present in the corpus striatum, inferior olivary nuclei and basis pontis. In the white matter the degree of destruction of axons and myelin sheaths varied greatly and was thought to be secondary to loss of neurones.

The four cases reported here, who came to autopsy, had in common diffuse degeneration of grey matter in many parts of the brain, particularly the cerebral cortex, cerebellar cortex, thalamus and basal ganglia. The changes in these regions consisted of reduction in the number of nerve cells with proliferation of microglia and astrocytes and fibrillary gliosis. There was some loss of myelin sheaths and axons in all cases, virtually complete in the first case where life had been prolonged.

There was no definite evidence in any of the cases of active neuronal disease; a few shrunken hyperchromatic nerve cells could be found but were not associated with neuronophagia and may have represented post-mortem change. In the fifth case ferrugination of a few neurones was found in the thalamus, and in the fourth case many neurones were vacuolated. These changes provide minimal evidence of neuronal degeneration and are nonspecific. A careful search was made in all cases for inclusion bodies, but none was identified. There was no evidence of lipid deposition within neurones, although numerous sections, stained by a variety of techniques (vide supra), were examined by several observers.

In all cases, in both biopsy and autopsy material, lipid was found in macrophages in damaged regions of both grey and white matter. It stained intensely red with Scharlach $R$, was non-metachromatic (toluidine blue) and non-haematoxylinophilic (Loyez). A few P.A.S. positive granules were present in macrophages in all cases. Anisotropic crystalline lipids were also present. These findings are similar to those associated with non-specific myelin breakdown occurring in relation to infarcts and traumatic lesions, and in multiple sclerosis and sudanophilic diffuse sclerosis, and are not regarded as being of significance in the differential diagnosis.

None of the cases provided evidence of inflammatory infiltration either of the meninges or of the brain. There was patchy leptomeningeal fibrosis in some areas. The blood vessels were unremarkable apart from slight pericapillary fibrosis and mild endothelial proliferation in severely damaged regions. In portions of cerebral cortex that were largely destroyed, capillaries appeared numerous, but this appearance may have been due to partial collapse of the tissue.

In the four cases examined consecutively by biopsy and autopsy, progression of the lesions in grey and white matter was clearly evident.

The presence of esterified cholesterol on chemical examination indicates an active demyelinating lesion which can be found in a number of disease processes. The amount is greatest in active plaques of multiple sclerosis and in sudanophilic diffuse sclerosis. However, in this latter condition there is an increase in total hexosamine not found in our five cases, and further there is evidence in our cases of cortical damage not seen in diffuse sclerosis. The degree of biochemical abnormalities is usually moderately less severe in cerebral tissue from infarcts and trauma.

The findings in our cases conform with those previously described and reinforce the clinical and pathological features of this separate disease entity. The aetiology, however, remains totally obscure. Various possible aetiological and pathogenic mechanisms have been suggested in the past, and certain ones will be discussed here.

Genetic Factors. Although many of the reported cases have been sporadic in occurrence, familial cases have been reported by Ford et al. (1951) and by Palinsky, Kozinn and Zahtz (1954). In our cases, the familial pattern is striking. It is apparent, too, that the age of onset and appearance of early symptoms were similar in each pair of siblings. Our data do not permit us to determine whether the familial pattern is due to heredity, chance or common environmental factors. 
Anoxia. Courville (1953) and many others have demonstrated that anoxia, produced in a variety of ways, is capable of producing widespread death of neurones throughout the nervous system. It is not surprising then that in this condition, where widespread loss of neurones is the outstanding pathological change, anoxia has been incriminated as a possible aetiological factor. It has been suggested that anoxia may have occurred either at birth or shortly thereafter, thus producing damage to the brain, or that following convulsions in infancy with accompanying anoxia death of neurones and concomitant development of mental and neurological deficits have resulted.

Several of the cases reviewed by Wolf and Cowen (1954) did in fact have abnormalities of the perinatal period that could have resulted in anoxia. In other cases such a history was not available, and in some, as in the case described by Christensen and Krabbe (1949), there was no evidence of perinatal anoxia. However, such a history, obtained in retrospect, cannot be considered reliable, especially when negative (Courville, 1953).

It should, however, be strongly emphasized that the history of normal mental and neuromuscular development for weeks, months, or even years, followed by rapid deterioration is not the pattern one would expect had the brain received an insult at birth sufficient to produce the damage seen in the brains of these cases. In addition, the studies of Keith, Norval and Holt (1953) failed to provide evidence that prolonged labour, asphyxia or delayed respiration caused any neurological abnormality in those premature or full-term infants who survived the postnatal period and who were followed for an average period of five years.

In 17 of the 32 cases collected by Wolf and Cowen the initial clinical abnormality was said to have been the occurrence of convulsions, and mental and motor changes followed. In the remainder, this relation was reversed or the available information was inadequate.

The cases reported herein provide additional evidence concerning these points. In only one of the five cases (Case 1) was a history of an abnormal labour or postnatal respiratory distress elicited. In the remainder, there was no evidence of any perinatal distress and this was true even in the fourth case, where a close study was made by the clinician of pregnancy, labour and the postnatal period.

With regard to anoxia during convulsions as a primary causative factor, in only two cases (Cases 3 and 5) was the first abnormality thought to be the occurrence of seizures. In the remainder motor and mental deterioration was well marked before the first convulsion.

The biochemical findings in these five cases are very similar but more severe than those seen in cerebral anoxia where the phospholipid loss and the amount of esterified cholesterol present is considerably less.

These data provide strong evidence that anoxia occurring either at birth or during convulsions is not the initiating cause of this disease process. However, it is more difficult to determine whether anoxia in relation to convulsions or for other reasons plays a secondary role in the production of the histological changes. Since all of the cases reported here had suffered from numerous epileptic seizures, many of them prolonged before cortical biopsy, this possibility remains open. It is impossible to state that the changes seen histologically were not due to anoxia, and speculation may not be rewarding. Further information may be available in the future from cases in which biopsy is performed before the onset of seizures, and from a study of cases where seizures can be controlled during life.

Metabolic Factors. Metabolic factors of aetiological significance were not found in our cases, but investigations were not specifically directed along these lines. In the third and fourth cases of this report, however, there was lymphocytic infiltration, fibrosis and bile-duct proliferation in portal areas of the liver, more severe than could reasonably be attributed simply to malnutrition during the latter part of the illness. These changes were not seen in Case 1 ; in the remaining two cases the state of the liver is not known, but there was no reason to suspect liver disease clinically.

In the second and fourth cases there was an increased excretion of certain amino acids. Unfortunately these tests were not performed on all cases.

It may be possible to differentiate cases of this condition from sudanophilic diffuse sclerosis, metachromatic leucodystrophy and the lipidoses on the basis of histological and chemical findings if cerebral biopsy is performed. The significant points are as follows.

1. The changes can be differentiated from those of the lipidoses by the absence of stainable lipid within nerve cells and by such lipid as there is being confined to microglia. It is uncommon in the early stages of amaurotic familial idiocy to have as much damage to the white matter as was seen in our cases.

2. Lipid deposition in the cortex, of the type found in our cases, has not been observed by us in the brains of sudanophilic diffuse sclerosis. 
3. Metachromatic material was not found in our cases in contrast to metachromatic leucodystrophy.

4. The results of the chemical examination of the brain exclude many of the types of lipidoses and leucodystrophies. The loss of phospholipid and the normal neuraminic acid level exclude amaurotic family idiocy, the normal total hexosamine excludes metachromatic leucodystrophy while the abnormalities in the cortex exclude sudanophilic diffuse sclerosis.

\section{Summary}

Five cases, in three families, of diffuse progressive degeneration of the brain in children, Alpers' disease, are reported. Cerebral biopsies had been performed in each case during life. In five cases confirmation was obtained by post-mortem examination (see addendum). Clinically and histologically the cases were similar to previously reported cases except that in two cases there were pathological changes in the livers which were more severe than could reasonably be attributed solely to malnutrition during the latter part of the illness. Biochemically the presence of esterified cholesterol in all cases in the white and in all but one case in the grey matter indicated progressive myelin degeneration. Various possible aetiological and pathogenic mechanisms are considered. Consideration is given to the biochemical and histological findings in the biopsies, which enable the condition to be distinguished from amaurotic family idiocy, metachromatic leucodystrophy and sudanophilic diffuse sclerosis.

\section{Addendum}

Case 2 died from bilateral bronchopneumonia on November 5, 1962, aged 3 years.

Autopsy. The brain weighed 372 g. Externally it showed diffuse cerebral and cerebellar atrophy. On section the cerebral cortex was thinner than normal, least noticeably in the frontal regions. The white matter was greatly reduced in amount and was replaced by firm yellowish coloured tissue. The basal ganglia appeared symmetrically small. The cerebellar hemispheres were slightly more atrophic than the vermis. The ventricles were generally dilated.
Microscopic Findings. In a portion of cerebral cortex and underlying white matter these were essentially similar to those seen in the biopsy from this case. Sudanophilic lipid was present in considerable amount in phagocytes in the white matter.

All other organs, including the liver, were not abnormal.

Biochemical Findings. The results obtained differed only slightly from those found at biopsy. Both cerebral white matter and cortex showed gross loss of myelin lipids with very considerable quantities of esterified cholesterol $(40 \%$ of total cholesterol in white and $16 \%$ in cortex). Further there was slightly less total phospholipid in the cortex at death than during life.

We should like to express our thanks to our many medical colleagues who have permitted us to report their findings and to the various technical staff for their assistance.

\section{REFERENCES}

Alpers, B. J. (1931). Diffuse progressive degeneration of the grey matter of the cerebrum. Arch. Neurol. Psychiat. (Chic.), $25,469$.

Christensen, E. and Krabbe, K. H. (1949). Poliodystrophia cerebri progressiva (infantilis). ibid., 61, 28.

Courville, C. B. (1953). Contributions for the Study of Cerebral Anoxia. San Lucas Press, Los Angeles.

Cumings, J. N. (1953). The cerebral lipids in disseminated sclerosis and in amaurotic family idiocy. Brain, 76, 551.

(1957). In Cerebral Lipidoses, ed. L. van Bogaert, J. N. Cumings and A. Lowenthal, p. 112. Blackwell Scientific Publications, Oxford.

Folch, J., Lees, M. and Sloane Stanley, G. H. (1957). A simple method for the isolation and purification of total lipides from animal tissues. J. biol. Chem., 226, 497.

Ford, F. R., Livingston, S. and Pryles, C. V. (1951). Familial degeneration of the cerebral grey matter in childhood with convulsions, myoclonus, spasticity, cerebellar ataxia, choreoathetosis, dementia, and death in status epilepticus. Differentiation of infantile and juvenile types. J. Pediat., 39, 33.

Greenfield, J. G., Blackwood, W., McMenemey, W. H., Meyer, A. and Norman, R. M. (1958). Neuropathology, p. 378. Arnold, London.

Keith, H. M., Norval, M. A. and Holt, A. B. (1953). Neurologic lesions in relation to the sequelae of birth injury. Neurology (Minneap.), 3, 139.

Long, C. and Staples, D. A. (1959). Determination of neuraminic acid in crude brain lipids. Biochem. J., 73, 385.

Palinsky, M., Kozinn, P. J. and Zahtz, H. (1954). Acute familial infantile heredodegenerative disorder of central nervous system. In Pediat. 45, 538.

Rusk, G. Y. and Nixon, C. E. (1927). Diffuse cortical sclerosis. A clinical and pathologic report of two cases. J. Lab. clin. Med., 12, 644 .

Svennerholm, L. (1957). In Cerebral Lipidoses, ed L. van Bogaert, J. N. Cumings and A. Lowenthal, p. 139. Blackwell Scientific Publications, Oxford.

Wolf, A. and Cowen, D. (1954). The cerebral atrophies and encephalomalacias of infancy and childhood. Ass. Res. nerv. Dis. Proc., 34, 199. 